\title{
The influence of social identity on self-worth, commitment, and effort in school-based youth sport
}

\author{
Luc J. Martin, Danny Balderson, Michael Hawkins, Kathleen Wilson \& Mark
} W. Bruner

To cite this article: Luc J. Martin, Danny Balderson, Michael Hawkins, Kathleen Wilson \& Mark W. Bruner (2017): The influence of social identity on self-worth, commitment, and effort in schoolbased youth sport, Journal of Sports Sciences, DOI: 10.1080/02640414.2017.1306091

To link to this article: http://dx.doi.org/10.1080/02640414.2017.1306091

Published online: 18 Mar 2017.

Submit your article to this journal $₫$

Llll Article views: 72

View related articles ־

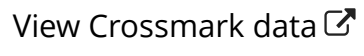




\title{
The influence of social identity on self-worth, commitment, and effort in school-based youth sport
}

\author{
Luc J. Martina, Danny Balderson ${ }^{b}$, Michael Hawkins', Kathleen Wilson ${ }^{d}$ and Mark W. Brunere
}

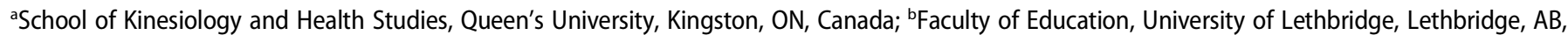
Canada; 'Department of Kinesiology and Physical Education, University of Lethbridge, Lethbridge, AB, Canada; ${ }^{\mathrm{d} D e p a r t m e n t}$ of Kinesiology, California State University Fullerton, Fullerton, CA, United States; 'School of Physical and Health Education, Nipissing University, North Bay, ON, Canada

\section{ABSTRACT}

The current study examined the influence of social identity for individual perceptions of self-worth, commitment, and effort in school-based youth athletes. Using a prospective research design, 303 athletes $\left(M_{\text {age }}=14.89, \mathrm{SD}=1.77 ; 133\right.$ female) from 27 sport teams completed questionnaires at 2 time points ( $\mathrm{T} 1$ - demographics, social identity; T2 - self-worth, commitment, effort) during an athletic season. Multilevel analyses indicated that at the individual level, the social identity dimension of ingroup ties (IGT) predicted commitment $(b=0.12, P=.006)$ and perceived effort $(b=0.14, P=.008)$, whereas in-group affect (IGA) predicted commitment $(b=0.25, P=.001)$ and self-worth $(b=2.62$, $P=.006)$. At the team level, means for IGT predicted commitment $(b=0.31, P<.001)$ and self-worth $(b=4.76, P=.024)$. Overall, social identity accounted for variance at both levels, ranging from $4 \%$ (selfworth) to $15 \%$ (commitment). Identifying with a group to a greater extent was found to predict athlete perceptions of self-worth, commitment, and effort. More specifically, at the individual level, IGT predicted commitment and effort, and IGA predicted commitment and self-worth. At the team level, IGT predicted commitment and self-worth.
ARTICLE HISTORY

Accepted 7 March 2017

\section{KEYWORDS}

Adolescents; multilevel analysis; identification; athletes; self-perceptions
Across the age spectrum, humans exhibit a desire for group membership and affiliation (Baumeister \& Leary, 1995). This attraction to inclusion can be observed through the many groups to which we belong (e.g., family, social circles, work groups), and there is extensive support for the various benefits derived from group membership (e.g., Forsyth, 2014). One such benefit involves the contribution to an individuals' identity - or in other words, their social identity. Social identity has been defined as "that part of an individual's self-concept which derives from his [or her] knowledge of his [or her] membership of a social group (or groups) together with the value and emotional significance attached to that membership" (Tajfel, 1981, p. 255). Gleaned from this general definition are the assumptions that people will be motivated to develop and sustain a positive selfconcept, and that this self-concept will be informed by the groups to which they belong.

Grounded in the research conducted by Tajfel and Turner (1979), social identity has been extensively investigated in social psychology (e.g., Brown, 2000). Importantly, group membership shapes individual self-evaluation (e.g., Tajfel \& Turner, 1979), and contributes to various psychological and behavioural outcomes such as improved self-esteem (e.g., Rubin \& Hewstone, 1998), group membership adherence (e.g., Spears, Doosje, \& Ellemers, 1999), and teamwork (e.g., Lembke \& Wilson, 1998). Interestingly, despite the extant literature supporting the salience of group identification, issues pertaining to its conceptualisation and measurement have been identified (e.g., Obst \& White, 2005). Consequently, and based on the definition advanced by Tajfel (1981), Cameron (2004) proposed a multidimensional conceptualisation involving 3 dimensions: cognitive centrality (CC; the importance that individuals place on group membership), in-group ties (IGT; the feelings of togetherness or belongingness experienced by the group member), and in-group affect (IGA; the positive feelings or emotions associated with membership). In concert with early work on social identity (Brown \& Williams, 1984), this conceptualisation highlights that different elements of group membership can influence people in diverse ways, and that some will be more central for certain people in comparison to others (Cameron, 2004). For example, whereas 1 individual might experience sheer enjoyment from their membership within a group, another may be more focused on the friendships that develop. As such, understanding how social identity generally, and the dimensions more specifically, influences individual cognitions and behaviours is an important endeavour.

In the organised interdependent sport setting, where athletes often undergo a selection process, are required to wear matching attire, and compete against other groups, membership is discernable. As such, social identity has received recent attention in this setting, with investigations demonstrating that coach behaviours or team outcomes (i.e., winning vs. losing) influence identity perceptions in elite adult athletes (e.g., De Backer et al., 2011; Zucchermaglio, 2005). Similarly, 
adults who identify with their teams to a greater extent are also less likely to adhere to unambitious team goals (i.e., potentially harmful for the team; Täuber \& Sassenberg, 2012). Clearly, identification with groups can both influence and be influenced by important group processes in older and elite sport populations.

In relation to youth sport, Murrell and Gaertner (1992) are often credited as the first to investigate social identity in athletes, demonstrating these perceptions to be associated with team winning percentage in a sample of high school football (American football) teams. More recently, and utilising Cameron's (2004) strength of identification scale, Bruner and colleagues have further explored this construct in the context of youth sport. In a preliminary investigation, they revealed perceptions of IGA to positively predict prosocial behaviours (e.g., encouragement, positive feedback) towards teammates (Bruner, Boardley, \& Côté, 2014). In addition, when athletes believed their teammates to influence personal and team outcomes (i.e., outcome interdependence), they experienced heightened perceptions of the 3 dimensions of social identity (Bruner, Eys, Evans, \& Wilson, 2015). Similarly, perceptions of groupness (i.e., the degree to which a collection of individuals is perceived to be a group) have also been found to improve social identity in youth athletes (Martin, Balderson, Hawkins, Wilson, \& Bruner, 2017). Taken together, these studies indicate that experiencing a sense of identity within a team can not only influence positive teammate interactions but can also be improved by perceiving the teams' efforts as a collective.

The current study sought to extend this preliminary work in youth sport by investigating pertinent correlates that are both theoretically and practically relevant. First, a salient outcome often described as emanating from group identification is selfworth/esteem (e.g., Rubin \& Hewstone, 1998). Membership within a group can facilitate personal or self-understanding (e.g., Hogg, 2006), and affiliation is an important method for regulating self-esteem (e.g., Tajfel \& Turner, 1979). This is particularly true in adolescent populations, and sport is one of the more prestigious groups for which young individuals seek affiliation (e.g., Sussman, Pokhrel, Ashmore, \& Brown, 2007). Interestingly, however, the social identity-self-esteem relationship has not been investigated in youth sport. Considering the importance of self-perceptions for continued sport participation (e.g., Weiss \& Ferrer-Caja, 2002) and positive youth development (e.g., Fraser-Thomas, Côté, \& Deakin, 2005), assessing its relationship to social identity is warranted.

Within the youth sport context, exploring involvement and commitment motives for young athletes is necessary, as participation rates are low (e.g., Downward, Lera-Lopez, \& Rasciute, 2014), and in fact, appear to decline with age (e.g., Balish, McLaren, Rainham, \& Blanchard, 2014; Canadian Heritage, 2013). Notably, identifying with a group can impact both actions and intentions (e.g., Tajfel \& Turner, 1979), and research involving exercise-based groups has demonstrated attendance to be associated with social identity in both school-based physical activity clubs (Bruner \& Spink, 2009) and adult running groups (Strachan, Shields, Glassford, \& Beatty, 2012). Commitment represents a psychological state regarding participation (e.g., Johnson, 1973), and in fact, has been highlighted as an indicator of participation patterns in youth sport (e.g., Scanlan, Carpenter, Schmidt, Simons, \& Keeler, 1993). Importantly, considering that adolescence is a period where individuals seek to expand their social connections beyond that of the family (e.g., Wagner, 1996), sport teams represent a salient group from which this desire for belongingness can be satiated (e.g., Allen, 2003). As a group affords individuals the opportunity to experience a collective self (i.e., their social identity), they are motivated to maintain inclusion within that social group (e.g., Leary \& Baumeister, 2000). Therefore, understanding whether perceptions of social identification could positively predict athlete commitment to involvement is relevant for youth sport settings.

Finally, effort has been introduced as a viable future direction for determining the influence of social identity in sport (Bruner, Dunlop, \& Beauchamp, 2014), and has been previously identified as a consequence of other social processes such as team norms and perceptions of team cohesion (e.g., Prapavessis \& Carron, 1997; Spink, Crozier, \& Robinson, 2013; Spink, Wilson, Nickel, \& Odnokon, 2005). Based on the theorising that the group represents a portion of an individuals' identity, that person will likely be motivated to represent the group favourably (e.g., Forsyth, 2014), and by extension, exude greater effort. In fact, self-presentation theory (Goffman, 1959) argues that group members attempt to maintain a social image in front of their peers, and when presented with performance situations (such as sport), will increase their effort. Consequently, increased amounts of effort might result from both the desire to better represent the group - as it symbolises a portion of an individual's identity (e.g., Tajfel \& Turner, 1979) - or because members are interested in maintaining their social image for their teammates (e.g., Goffman, 1959). In a youth sport setting, where the provision of physical activity and sustained long-term engagement are desired, the tendency to increase effort based on identity perceptions could be an impactful finding.

Therefore, based on recent research in youth sport, and the general understanding of the impact of identity perceptions for individuals (e.g., Brown, 2000), the current project sought to extend this research with adolescent athletes. Specifically, the purpose was to determine the predictability of social identity pertaining to the way athletes think about themselves (i.e., self-worth), the extent to which they intend to remain involved with their teams (i.e., commitment), and the degree to which these perceptions influence their sport-related work output (i.e., effort). In addition, although social identity perceptions are inherently personal (i.e., the individual level), teams composed of athletes who identify strongly with the group (i.e., the team level) might provide additional benefits to participating members. As such, a prospective research design involving multilevel modelling will enable the identification of the impact obtained when perceptions of social identity are represented among the entire group, as compared to solely at the individual level.

\section{Methods}

\section{Subjects}

Subjects included 380 youth athletes from a province in Western Canada. Ultimately, 303 athletes $\left(M_{\text {age }}=14.89\right.$, 
$\mathrm{SD}=1.77 ; 133$ females) completed questionnaires at 2 data collection periods during their athletic season, which represent $80 \%$ of those who completed the questionnaires during the first data collection period. Subjects were members of 27 interdependent school sport teams ( $k=12$ basketball, $k=8$ rugby, $k=4$ football, $k=2$ baseball, $k=1$ volleyball) that were composed of 11.22 members $(S D=5.96)$. Athletes had participated in their sport for 4.78 years $(S D=2.87)$ and had been on their current teams for 2.16 years $(S D=1.24)$. Finally, the majority of the population was Caucasian (87\%), with representations from Native Aboriginal (3.3\%), Black (1.3\%), Chinese $(0.3 \%)$, Filipino $(0.3 \%)$, Japanese $(0.3 \%)$, and combination/ other $(7.5 \%)$.

\section{Measures}

\section{Social identity}

The 3 dimensions of social identity (i.e., IGT, CC, IGA) were assessed using a previously adapted version of the questionnaire developed by Cameron (2004) within a youth sport population (Bruner et al., 2014). Specifically, 12 items are answered on a 7-point Likert-type scale anchored at the extremes with 1 (Strongly disagree) and 7 (Strongly agree). Example items are "I feel strong ties to other members of this team" (IGT), "I often think about the fact that I am a team member" (CC), and "Generally, I feel good when I think about myself as a team member" (IGA). There are 5 negatively worded items that must be reversed scored, and previous research has demonstrated the validity and reliability of this inventory (Cameron, 2004; Obst \& White, 2005). With the current sample, CC was removed from further analyses due to poor reliability $(a=.51)$, yet both IGT $(a=.71)$ and IGA $(a=.74)$ were acceptable.

\section{Self-worth}

Self-worth was assessed using the Washington SelfDescription Questionnaire (WSDQ; Smoll, Smith, Barnett, \& Everett, 1993). The WSDQ involves 14 items that assess global self-evaluations (e.g., "I think pretty highly of myself"). The reading level is set for children as young as 7 years of age (Flesch-Kincaid index), and there are items that reflect both positive $(n=6)$ and negative $(n=8)$ evaluations. For the current study, subjects responded to a 5-point Likert-type scale anchored with 1 (Not at all like me) and 5 (Very much like me). Previous research has demonstrated adequate internal consistency and test-retest reliability (e.g., Smoll et al., 1993), and the reliability was acceptable with the current sample $(a=.90)$.

\section{Commitment}

Commitment was assessed using adapted items from the Sport Commitment Model (Scanlan et al., 1993) previously utilised by Weiss and Smith (2002) with younger populations. There are 4 items based on a 5-point Likert-type scale anchored at the extremes with 1 (Not at all dedicated) and 5 (Very dedicated); thus, higher scores reflect greater commitment (e.g., "How dedicated are you to playing in this sport?"). Previous research with similar populations has demonstrated good internal consistency values (e.g., Scanlan et al., 1993;
Weiss \& Smith, 2002), and it was also acceptable with the current sample $(a=.90)$.

\section{Self-reported effort}

Individual perceptions of exerted effort were measured based on a 2-item scale (e.g., "How hard did you work in your last competition/game?"), whereby a mean score was computed for each subject. Similar items have been used successfully in previous sport research (e.g., Spink et al., 2013, 2005), yet these were with older adolescent populations. As such, the reading level of both items was set for children as young as 7 years of age (Flesch-Kincaid index), and responses were provided on a 5-point Likert-type scale anchored at the extremes with 1 (Not hard at all) and 5 (Very hard) - thus, higher scores reflected greater amounts of exerted effort.

\section{Procedure}

After obtaining institutional and school board ethical approvals, athletic directors were contacted to obtain permission to approach their coaches. Approximately 50 coaches were invited to have their teams participate in the study, and the research team attended team practices to introduce the project to the athletes and to distribute information letters and parental/guardian consent forms. Once parental/guardian consent and athlete assent were obtained, the research team returned to have the athletes' complete questionnaires during the early stages of the season (Time 1 at 3-6 weeks; demographics, social identity) and again towards the end of the season (Time 2 at 8-12 weeks; self-worth, commitment, effort). The first data collection period took place towards the beginning to the middle stages of the group's existence, which was meant to provide sufficient time for group perceptions and relationships to cultivate. Considering the dynamic nature of groups (e.g., Carron \& Brawley, 2000), and that changes in group perceptions have been identified across a short period (e.g., Evans \& Eys, 2015), the second data collection took place approximately 1 month later. The 2 data collection periods satisfy temporal ordering, whereby the independent variables are taken before the dependent variables (e.g., Munro, 2005). On both occasions, the questionnaires took 15-20 min to complete, and were distributed prior to or after team practices.

\section{Analyses}

Descriptive and bivariate statistics were calculated and assumptions for normality were assessed for the study variables. In addition, as the purpose of the study was to assess whether social identity could predict specific outcome variables, an independent samples $t$-test was conducted to determine differences in perceptions of social identity between athletes who completed questionnaires at both time points $(n=303)$ and those who were only present at Time $1(n=77)$. There were no significant differences between these groups $(P>.05)$. In relation to missing values for the 303 athletes included in the analyses, these values (less than $5 \%$ of scalescored items) were imputed via series-mean replacement. For the main analyses, multilevel analyses were computed for 
each outcome variable (i.e., self-worth, commitment, effort) with the social identity dimensions (i.e., IGT, IGA) entered at Level 1 and the team means for IGT and IGA entered at Level 2. A multilevel modelling approach via hierarchical linear modelling software (HLM7; Raudenbush, Bryk, Cheong, Condon, \& Du Tolt, 2011) enabled the researchers to account for the nested nature of the current sample (i.e., youth athletes were members of their school sport teams). Using restricted maximum likelihood estimation, null models were first computed for each of the 3 outcome variables to determine level of independence. Next, models were specified with IGT and IGA entered at Level 1 (individual level) centred around the team average (i.e., group-mean centred). Note that groupmean centring was introduced to account for the nesting within sport teams (e.g., Enders \& Tofighi, 2007). Finally, the team means for both IGT and IGA were included on the intercept using grand-mean centring, which establishes a meaningful 0 point on the scales (e.g., Enders \& Tofighi, 2007). Pearson correlation coefficient, $r$, effect sizes $(0.10=$ small, $0.30=$ medium, $0.50=$ large; Field, 2016) were also provided. The fixed and random slopes were compared, and assumptions for multilevel models were assessed (e.g., normality of residuals, misspecification, and homogeneity of variance at Levels 1 and 2).

\section{Results}

Descriptive and bivariate statistics for the main study variables are presented in Table 1. For large sample sizes, visual inspection of skewness and kurtosis is recommended in lieu of formal inference tests (e.g., Tabachnick \& Fidell, 2013), and the dependent variables (i.e., self-worth, commitment, effort) appeared to be negatively skewed. As the skewness was in the same direction for these variables and the sample size was greater than 200, a substantive difference in the analysis is not expected (Tabachnick \& Fidell, 2013; Waternaux, 1976). In addition, univariate normality for the residuals was identified via Q-Q Plots and histograms, and misspecification was evidenced through a lack of distinct linear or curvilinear pattern in scatter plots for all Level 1 and 2 predictors. Finally, multivariate normality was supported through the Mahalanobis' distance (observed value) and the chi-square distribution (expected value) demonstrating a 45-degree angle in a scatter plot (e.g., Tabachnick \& Fidell, 2013).

To determine whether a multilevel approach was necessary (that is, there was group-level variance in the outcome variables), null models without predictors (i.e., IGT, IGA) were computed for self-worth, commitment, and effort. These null models provide within-team variance at Level 1 (individual level) and between-team variance at Level 2 (team level).

Table 1. Descriptive and bivariate statistics for study variables.

\begin{tabular}{lrrrrrrr}
\hline & M & SD & 1 & 2 & 3 & 4 & 5 \\
\hline (1) Self-worth & 56.72 & 9.39 & - & $.27^{* *}$ & $.30^{* *}$ & $.14^{* *}$ & $.17^{* *}$ \\
(2) Commitment & 4.52 & .68 & & - & $.42^{* *}$ & $.32^{* *}$ & $.34^{* *}$ \\
(3) Effort & 4.43 & .66 & & & - & $.23^{* *}$ & $.21^{* *}$ \\
(4) In-group ties & 5.01 & .84 & & & - & $.49^{* *}$ \\
(5) In-group affect & 5.39 & .67 & & & & \multicolumn{2}{c}{-} \\
\hline
\end{tabular}

$N=303$. Scores for self-worth range from 14-70, commitment and effort range from $1-5$, IGT and IGA range from $1-7 .{ }^{* *} P \leq .01$
The intraclass correlations (ICCS) were .06 (self-worth), .07 (commitment), and .07 (effort), thus demonstrating that between $6 \%$ and $7 \%$ of the response variance could be attributed to nesting within teams. Specifically, members of the same team shared similarities in terms of the outcome variables.

Table 2 provides a summary of the results. With regard to the main analyses, the social identity dimensions (i.e., IGT, IGA) were included as Level 1 variables and teams IGT and IGA (i.e., IGTM, IGAM) were included as Level 2 variables for each of the 3 outcome variables. At Level 1 (individual level), higher perceptions of IGT predicted increased commitment $(b=.12, P=.006, r=.16)$ and individual effort ( $b=.14, P=.008, r=.16)$, whereas IGA significantly predicted self-worth $(b=2.62, P=.006, r=.16)$ and commitment $(b=.25, P=.001, r=.20)$. At Level 2 (team level), means for IGT predicted self-worth $(b=4.76, P=.024$, $r=.44)$ and commitment $(b=.31, P<.001, r=.61)$, however, the means for IGA failed to predict any of the outcome variables. Social identity accounted for variance at both the team and individual levels, ranging from $4 \%$ (self-worth) to $15 \%$ (commitment).

\section{Discussion}

The purpose of the current study was to examine the predictability of perceptions of social identity for individual outcomes in a school-based youth sport setting. Utilising a prospective research design involving multilevel modelling, specific dimensions of social identity at both the individual and team levels were found to be significant predictors of individual self-worth, commitment, and effort. In recognising the numerous outcome variables of interest, the following sections will involve discourse in relation to each of the predicted relationships, in addition to discussions pertaining to limitations and implications of the research.

Perceptions of both IGT (e.g., feelings of togetherness or belongingness) and IGA (e.g., positive feelings or emotions associated with membership) significantly predicted followup assessments of commitment in youth athletes. These results support our hypotheses, and are consistent with the literature. For example, in exercise contexts, identification with

\begin{tabular}{lccc}
\multicolumn{4}{c}{ Table 2. Coefficients for social identity predicting self-worth, commitment, and effort. } \\
\hline $\begin{array}{c}\text { Self-worth } \\
(S E)\end{array}$ & $\begin{array}{c}\text { Commitment (SE) } \\
\text { Fixed effects }\end{array}$ & Effort (SE) \\
\hline Level 1 & $56.53(0.65)^{* *}$ & $4.52(0.04)^{* *}$ & $4.42(0.05)^{* *}$ \\
Intercept & $0.22(0.94)$ & $0.12(0.04)^{* *}$ & $0.14(0.05)^{* *}$ \\
In-group ties (IGT) & $2.62(0.95)^{* *}$ & $0.25(0.07)^{* *}$ & $0.11(0.07)$ \\
In-group affect (IGA) & & & \\
Level 2 & $4.76(1.98)^{*}$ & $0.31(0.08)^{* *}$ & $0.05(0.14)$ \\
In-group ties mean & & & \\
(IGTM) & $-3.71(3.38)$ & $0.20(0.13)$ & $0.20(0.20)$ \\
In-group affect mean & & & \\
(IGAM) & $4 \%$ & $15 \%$ & $4 \%$ \\
Overall & $3 \%$ & $9 \%$ & $5 \%$ \\
Level 1 & $15 \%$ & $79 \%$ & $4 \%$ \\
Level 2 & 0.06 & 0.07 & 0.07 \\
ICC & 2187.39 & 529.29 & 599.83 \\
-2*log likelihood & &
\end{tabular}


a group increases adherence in both youth and adults (e.g., Bruner \& Spink, 2009; Strachan et al., 2012). Although actual adherence and commitment motives are markedly different, Scanlan, Russell, Magyar, and Scanlan (2009) define commitment as a "psychological construct reflecting the desire and resolve to persist in an endeavour over time" (p. 686). Consequently, while we are not insinuating that our results automatically suggest a relationship to adherence in sport, youth have identified socially oriented motives for both participation (e.g., to make new friends; Weiss \& Petlichkoff, 1989) and dropout (e.g., lack of quality friendships; Crane \& Temple, 2015). As such, the fact that increased perceptions of identity represented by feelings of belongingness and positive affect can predict athlete commitment is an important contribution, and its relevance is supported by the utility of social processes for the enrichment of sport experiences (e.g., Knight \& Holt, 2011).

With regard to the other outcome variables, IGT predicted effort but not self-worth. Conceptually, IGT is closely related to other group dynamics constructs such as cohesion, which has previously demonstrated an association with effort (e.g., Spink et al., 2005). As a proportion of an individuals' identity is constructed from the perception of ties with team members, athletes might have demonstrated increased effort to preserve their social image (e.g., Goffman, 1959), or to more favourably represent the team (e.g., Forsyth, 2014). The lack of significance with self-worth is nonetheless surprising, as group identification is said to influence self-understanding (e.g., Hogg, 2006). In this specific sport setting, where athletes were queried about their commitment to their teams and the effort exerted during competitions and practices, perhaps a more specific form of self-evaluation such as task selfefficacy would have demonstrated a significant relationship. In addition, investigations pertaining to various levels of sport competitiveness (e.g., school-based, recreational club, elite club) could be a future direction of interest, whereby athletes participating at more elite levels and who spend a greater amount of time with their teammates may experience greater self-worth due to IGT.

In terms of IGA, this dimension predicted self-worth but not effort. The consistent positive feelings or emotions derived from group membership in sport could have contributed to these positive self-evaluations (e.g., Sussman et al., 2007). If the affective associations with group identification are predominantly positive, it is perhaps not surprising that these translate to more constructive self-perceptions (e.g., Hogg, 2006; Tajfel \& Turner, 1979). Interestingly, whereas positive affective responses to team membership translated to improved cognitions, they may not be proximal enough to translate to actual behaviours (i.e., effort). Generally, the social identity dimensions are likely to influence different outcomes to varying degrees, which support the original theorising of Cameron (2004) for developing the multidimensional model. Research should continue to investigate the intricacies of the dimensions of social identity for youth athletes (e.g., Bruner et al., 2014). As several examples, the dimensions are likely to represent varying levels of importance for different athletes and might more significantly influence certain constructs (e.g., IGT to friendship quality, IGA to sport satisfaction) in comparison to others. As such, continued investigations pertaining to relevant correlates of social identity in youth athletes would further our understanding of the implications for this population.
Finally, the utilisation of a multilevel modelling approach enabled the identification of team member similarities in outcome variable perceptions. As such, it was of interest to determine whether team-level perceptions of social identity could predict self-worth, commitment, and effort. Although no significant relationships were identified for IGA, the team-level means for IGT predicted self-worth and commitment. One possible explanation for this finding is the tendency for the IGT dimension to encapsulate perceptions of the entire team through togetherness and belongingness with teammates (e.g., Cameron, 2004) - in comparison to the more introspective IGA dimension. Indeed, and as previously alluded to, the IGT dimension aligns with group-related constructs such as cohesion and connectedness, where associations with outcomes such as self-worth and commitment have been identified (e.g., Martin, Carron, Eys, \& Loughead, 2013; Spink, Wilson, \& Odnokon, 2010). This is an important consideration as social identity is inherently a personal construct, albeit largely influenced by the group, and perhaps the IGT dimension can also represent athletes' shared perceptions of the interdependent "ties" experienced among teammates.

Notwithstanding the information gleaned from the current study, limitations warrant discussion. This research represents an exploratory investigation of social identity in youth sport using the conceptual model advanced by Cameron (2004). As the reliability of the CC dimension was not acceptable, it was subsequently omitted from the analyses. This issue has occurred with another study in a similar population (e.g., Bruner et al., 2014), which limits our understanding of CC as it pertains to youth athletes. More recently, Bruner and colleagues (2015) introduced a positively worded version of the strength of identification scale (Cameron, 2004), and demonstrated adequate reliability for all 3 dimensions. Although the use of mixed items can be beneficial for identifying response acquiescence (e.g., Block, 1965; Nunnally, 1978), it can also negatively influence internal reliability due to confusion or misinterpretation (e.g., Spector, 1992). Researchers have highlighted the opportunity for further modifications to the questionnaire (Obst \& White, 2005), and as such, future sport research could utilise the positively worded adaptation advanced by Bruner et al. (2015).

Another limitation and potential for future research pertains to the 3 outcome variables assessed at Time 2 . Notably, whereas the focus of the current study was to establish preliminary predictive relationships in a youth sport setting, it is possible that self-worth could act as a mediator between the social identity and commitment and effort relationships. Self-perceptions can influence intentions and eventual behaviour (e.g., Ajzen, 1985), and exploring self-worth as a potential mechanism for the effects on commitment and effort would be worthwhile. Previous research with social identity in youth sport has identified the significance of mediators (e.g., cohesion) for subsequent behaviours (e.g., prosocial and antisocial towards teammates and opponents; Bruner et al., 2014), and future research could consider the addition of a third time point with the current outcomes to properly investigate this possibility.

Finally, the findings from the current study offer several practical implications for the youth sport setting. Indeed, as groups represent a subjective social reality as much as an objective 
physical reality (Forsyth \& Burnette, 2010), an individualised construct such as social identity could prove to be quite powerful for coaches (e.g., Rees, Haslam, Coffee, \& Lavallee, 2015). Research has identified an over-reliance of team-building activities focused on group-based constructs such as cohesion (Bruner, Eys, Beauchamp, \& Côté, 2013), and coaches could benefit from specifically ensuring that athletes associate team membership with favourable emotions and feelings (i.e., IGA) and are provided with opportunities to experience a sense of togetherness with teammates (i.e., IGT). These could be facilitated by creating a team climate that holds values and demonstrates a vision that is closely aligned with that of the athletes. In fact, recent research advocating a social identity approach to leadership highlighted the importance of having the leader epitomise the group ideal (i.e., the way we expect our group members to behave) and create a compelling vision for the team (Slater, Coffee, Barker, \& Evans, 2014). In addition, tailoring traditional team-building activities geared towards increasing the physical proximity among athletes (e.g., carpooling during team travel or seating assignments in the locker room; Paradis \& Martin, 2012) could reinforce consistent quality interactions. Importantly, enabling the development of rich bonds between athletes and creating an environment conducive to positive affect can improve social identity - and by extension, important individual outcomes such as self-worth, commitment, and effort.

\section{Conclusion}

As a summary, this article represents a prospective research design utilising multilevel analyses to investigate the influence of social identity on athlete perceptions of self-worth, commitment, and effort in a school-based youth sport sample. Despite the exploratory nature of the study, the multilevel analyses and sample size increase our confidence in the results. In addition, the research questions investigated and the identified limitations provide opportunities for sport researchers and practitioners to build upon in future research.

\section{Acknowledgement}

This work was supported by the Alberta Centre for Child, Family, and Community Research (ACCFC) under a Seed Grant (\#13SG).

\section{Disclosure statement}

No potential conflict of interest was reported by the authors.

\section{Funding}

This work was supported by the Alberta Centre for Child, Family and Community Research (ACCFC) under a Seed Grant \#13SG.

\section{References}

Ajzen, I. (1985). From intention to actions: A theory of planned behavior. In J. Kuhl \& J. Beckman (Eds.), Action control: From cognition to behavior (pp. 11-39). Heidelberg, Germany: Springer.

Allen, J. B. (2003). Social motivation in youth sport. Journal of Sport \& Exercise Psychology, 25, 55-567. doi:10.1123/jsep.25.4.551
Balish, S. M., McLaren, C., Rainham, D., \& Blanchard, C. (2014). Correlates of youth sport attrition: A review and future directions. Psychology of Sport and Exercise, 15, 429-439. doi:10.1016/j.psychsport.2014.04.003

Baumeister, R. F., \& Leary, M. R. (1995). The need to belong: Desire for interpersonal attachments as a fundamental human motivation. Psychological Bulletin, 117, 497-529. doi:10.1037/0033-2909.117.3.497

Block, J. (1965). The challenge of response sets: Unconfounding meaning, acquiescence, and social desirability in the MMPI. New York, NY: Meredith Publishing Company.

Brown, R. (2000). Social identity theory: Past achievements, current problems, and future challenges. European Journal of Social Psychology, 30, 745-778. doi:10.1002/1099-0992

Brown, R., \& Williams, J. (1984). Group identification: The same thing to all people? Human Relations, 37, 547-564. doi:10.1177/001872678403700704

Bruner, M. W., Boardley, I. D., \& Côté, J. (2014). Social identity and prosocial and antisocial behavior in youth sport. Psychology of Sport and Exercise, 15(1), 56-64. doi:10.1016/j.psychsport.2013.09.003

Bruner, M. W., Dunlop, W., \& Beauchamp, M. R. (2014). A social identity perspective on group processes in sport and exercise. In $M$. R. Beauchamp \& M. A. Eys (Eds), Group dynamics in exercise and sport psychology (2nd ed., pp. 38-52). New York, NY: Routledge.

Bruner, M. W., Eys, M. A., Beauchamp, M. R., \& Côté, J. (2013). Examining the origins of team building in sport: A citation network and genealogical approach. Group Dynamics: Theory, Research, and Practice, 17(1), 30-42. doi:10.1037/a0030114

Bruner, M. W., Eys, M. A., Evans, M. B., \& Wilson, K. (2015). Interdependence and social identity in youth sport teams. Journal of Applied Sport Psychology, 27, 351-358. doi:10.1080/10413200.2015.1010661

Bruner, M. W., \& Spink, K. S. (2009, June). Investigating the relationship between social identity and exercise adherence in adolescent. Paper session resented at the $12^{\text {th }}$ Work Congress of the International Society of Sport Psychology, Marrakech, Morocco.

Cameron, J. E. (2004). A three-factor model of social identity. Self and Identity, 3, 239-262. doi:10.1080/13576500444000047

Canadian Heritage. (2013). Sport participation 2010: Research paper. Retrieved from http://publications.gc.ca/collections/collection_2013/ pc-ch/CH24-1-2012-eng.pdf

Carron, A. V., \& Brawley, L. R. (2000). Cohesion: Conceptual and measurement issues. Small Group Research, 31, 89-106. doi:10.1177/104649640003100105

Crane, J., \& Temple, V. (2015). A systematic review of dropout from organized sport among children and youth. European Physical Education Review, 21(1), 114-131. doi:10.1177/1356336X14555294

de Backer, M., Boen, F., Ceux, T., de Cuyper, B., Høigaard, R., Callens, F., ... vande Broek, G. (2011). Do perceived justice and need support of the coach predict team identification and cohesion? Testing their relative importance among top volleyball and handball players in Belgium and Norway. Psychology of Sport and Exercise, 12, 192-201. doi:10.1016/j. psychsport.2010.09.009

Downward, P., Lera-López, F., \& Rasciute, S. (2014). The correlates of sports participation in Europe. European Journal of Sport Science, 14(6), 592 602. doi:10.1080/17461391.2014.880191

Enders, C. K., \& Tofighi, D. (2007). Centering predictor variables in crosssectional multilevel models: A new look at an old issue. Psychological Methods, 12, 121-138. doi:10.1037/1082-989X.12.2.121

Evans, M. B., \& Eys, M. A. (2015). Collective goals and shared tasks: Interdependence structures and perceptions of individual sport team environments. Scandinavian Journal of Medicine \& Science in Sports, 25 (1), e139-e148. doi:10.1111/sms.12235

Field, A. (2016). An adventure in statistics: The reality enigma. Thousand Oaks, CA: Sage Publications Inc.

Forsyth, D. R. (2014). Group dynamics (6th ed.). Wadsworth, CA: Cengage Learning.

Forsyth, D. R., \& Burnett, J. L. (2010). Group processes. In E. R. Baumeister and E. Finkel (Eds.), Advanced social psychology (pp. 495-534). New York, NY: Cambridge.

Fraser-Thomas, J. L., Côté, J., \& Deakin, J. (2005). Youth sport programs: An avenue to foster positive youth development. Physical Education \& Sport Pedagogy, 10(1), 19-40. doi:10.1080/1740898042000334890

Goffman, E. (1959). The presentation of self in everyday life. Garden City, NY: Doubleday. 
Hogg, M. A. (2006). Social identity theory. In P. J. Burke (Eds.), Contemporary social psychological theories (pp. 111-136). Stanford, CA: Stanford University Press.

Johnson, M. P. (1973). Commitment: A conceptual structure and empirical application. Sociological Quarterly, 14, 395-406. doi:10.1111/ tsq.1973.14.issue-3

Knight, C. J., \& Holt, N. L. (2011). Sport participation during childhood and adolescence. In N. L. Holt \& M. Talbot (Eds.), Lifelong engagement in sport and physical activity: Participation and performance across the lifespan (pp. 9-18). New York, NY: Routledge.

Leary, M. R., \& Baumeister, R. F. (2000). The nature and function of self-esteem: Sociometer theory. Advances in Experimental Social Psychology, 32, 1-62.

Lembke, S., \& Wilson, G. M. (1998). Putting the 'team' into teamwork: Alternative theoretical contributions for contemporary management practice. Human Relations, 51, 927-944. doi:10.1177/001872679805100704

Martin, L. J., Balderson, D., Hawkins, M., Wilson, K., \& Bruner, M. W. (2017), Groupness and leadership perceptions in relation to social identity in youth sport. Journal of Applied Sport Psychology. doi:10.1080/ 10413200.2016.1238414

Martin, L. J., Carron, A. V., Eys, M. A., \& Loughead, T. M. (2013). Validation for the child sport cohesion questionnaire (CSCQ). Measurement in Physical Education and Exercise Science, 17, 105-119. doi:10.1080/ 1091367X.2013.761023

Munro, B. H. (2005). Statistical methods for health care research. Philadelphia, PA: Lippincott Williams \& Wilkins.

Murrell, A. J., \& Gaertner, S. L. (1992). Cohesion and sport team effectiveness: The benefit of a common group identity. Journal of Sport \& Social Issues, 16(1), 1-14. doi:10.1177/019372359201600101

Nunnally, J. C. (1978). Psychometric Theory. New York, NY: McGraw-Hill.

Obst, P., \& White, K. (2005). Three-dimensional strength of identification across group memberships: A confirmatory factor analysis. Self and Identity, 4(1), 69-80. doi:10.1080/13576500444000182

Paradis, K. F., \& Martin, L. J. (2012). Team building in sport: Linking theory and research to practical application. Journal of Sport Psychology in Action, 3(3), 159-170. doi:10.1080/21520704.2011.653047

Prapavessis, H., \& Carron, A. V. (1997). Sacrifice, cohesion, and conformity to norms in sport teams. Group Dynamics: Theory, Research, and Practice, 1, 231-240. doi:10.1037/1089-2699.1.3.231

Raudenbush, S., Bryk, A., Cheong, Y. F., Condon, R. T., \& Du Tolt, M. (2011). HLM 7: Hierarchical linear \& nonlinear modeling. Lincolnwood, IL: Scientific Software International.

Rees, T., Haslam, S. A., Coffee, P., \& Lavallee, D. (2015). A social identity approach to sport psychology: Principles, practice, and prospects. Sports Medicine, 45(8), 1083-1096. doi:10.1007/s40279-015-0345-4

Rubin, M., \& Hewstone, M. (1998). Social Identity Theory's self-esteem hypothesis: A review and some suggestions for clarification. Personality and Social Psychology Review, 2(1), 40-62. doi:10.1207/s15327957pspr0201_3

Scanlan, T. K., Carpenter, P. J., Schmidt, G. W., Simons, J. P., \& Keeler, B. (1993). An introduction to the sport commitment model. Journal of Sport \& Exercise Psychology, 15, 1-15. doi:10.1123/jsep.15.1.1

Scanlan, T. K., Russell, D. G., Magyar, T. M., \& Scanlan, L. A. (2009). Project on elite athlete commitment (PEAK): III. An examination of the external validity across gender, and the expansion and clarification of the sport commitment model. Journal of Sport \& Exercise Psychology, 31, 685-705. doi:10.1123/ jsep.31.6.685

Slater, M. J., Coffee, P., Barker, J. B., \& Evans, A. L. (2014). Promoting shared meanings in group memberships: A social identity approach to leadership in sport. Reflective Practice, 15(5), 672-685. doi:10.1080/ 14623943.2014.944126
Smoll, F. L., Smith, R. E., Barnett, N. P., \& Everett, J. J. (1993). Enhancement of children's self-esteem through social support training for youth sport coaches. Journal of Applied Psychology, 78(4), 602-610. doi:10.1037/ 0021-9010.78.4.602

Spears, R., Doosje, B., \& Ellemers, N. (1999). Commitment and the context of social perception. In N. Ellemers, R. Spears, \& B. Boosje (Eds.), Social identity: Context, commitment, content (pp. 59-83). Oxford, England: Blackwell.

Spector, P. E. (1992). Summated rating scale construction: An introduction. [University Paper series on Quantitative Applications in the Social Sciences, series no. 07-082]. Newbury Park, CA: Sage.

Spink, K. S., Crozier, A. J., \& Robinson, B. (2013). Examining the relationship between descriptive norms and perceived effort in adolescent athletes: Effects of different reference groups. Psychology of Sport and Exercise, 14, 813-818. doi:10.1016/j.psychsport.2013.06.006

Spink, K. S., Wilson, K., Nickel, D., \& Odnokon, P. (2005, October). Examining the relationship between task cohesion and perceived effort in ice hockey players using a multilevel approach. Paper presented the Canadian Society of Psychomotor Learning and Sport Psychology, Niagara Falls, Ontario, Canada.

Spink, K. S., Wilson, K., \& Odnokon, P. (2010). Examining the relationship between cohesion and return to team in elite athletes. Psychology of Sport and Exercise, 11, 6-11. doi:10.1016/j.psychsport.2009.06.002

Strachan, S. M., Shields, C. A., Glassford, A., \& Beatty, J. (2012). Role and group identity and adjustment to the possibility of running group disbandment. Journal of Sport \& Exercise Psychology, 13, 436-443. doi:10.1016/j.psychsport.2012.01.007

Sussman, S., Pokhrel, P., Ashmore, R. D., \& Brown, B. B. (2007). Adolescent peer group identification and characteristics: $A$ review of the literature. Addictive Behaviors, 32(8), 1602-1627. doi:10.1016/j.addbeh.2006.11.018

Tabachnick, B. G., \& Fidell, L. S. (2013). Using multivariate statistics (6th ed.). New Jersey, NY: Pearson Education, Inc.

Tajfel, H. (1981). Human groups and social categories: Studies in social psychology. Cambridge, England: Cambridge University Press.

Tajfel, H., \& Turner, J. (1979). An integrative theory of intergroup conflict. In W. G. W. Austin (Ed.), The social psychology of intergroup relations ( $\mathrm{pp}$. 33-47). Monterey, CA: Brooks-Cole.

Täuber, S., \& Sassenberg, K. (2012). The impact of identification on adherence to group norms in team sports: Who is going the extra mile? Group Dynamics: Theory, Research, and Practice, 16, 231-240. doi:10.1037/a0028377

Wagner, W. (1996). Facilitating optimal development in adolescents. The Counselling Psychologist, 24, 3567-3569. doi:10.1177/ 0011000096243001

Waternaux, C. M. (1976). Asymptotic distribution of the sample roots for a nonnormal population. Biometrika, 63(3), 639-645. doi:10.1093/biomet/ 63.3.639

Weiss, M. R., \& Ferrer-Caja, E. (2002). Motivational orientations and sport behavior. In T. S. Horn (Eds), Advances in sport psychology (2nd ed., pp. 101-170). Champaign, IL: Human Kinetics.

Weiss, M. R., \& Petlichkoff, L. (1989). Children's motivation for participation in and with- drawal from sport: Identifying the missing links. Pediatric Exercise Science, 1, 195-211. doi:10.1123/pes.1.3.195

Weiss, M. R., \& Smith, A. L. (2002). Friendship quality in youth sport: Relationship to age, gender, and motivation variables. Journal of Sport \& Exercise Psychology, 24(4), 420-437. doi:10.1123/jsep.24.4.420

Zucchermaglio, C. (2005). Who wins and who loses: The rhetorical manipulation of social identities in a soccer team. Group Dynamics: Theory, Research, and Practice, 9, 219-238. doi:10.1037/1089-2699.9.4.219 